Journal of Advanced Research in Fluid Mechanics and Thermal Sciences

\title{
Multi-Circuit Air-Conditioning System Modelling for Temperature Control
}

\author{
Ibrahim Oleolo ${ }^{1}$, Hayati Abdullah ${ }^{1,}{ }^{*}$, Maziah Mohamad ${ }^{1}$, Mohammad Nazri Mohd Jaafar ${ }^{1}$, Akmal \\ Baharain $^{1}$, Sapiah Sulaiman ${ }^{2}$
}

\footnotetext{
School of Mechanical Engineering, Faculty of Engineering, Universiti Teknologi Malaysia, 81310 UTM Johor Bahru, Johor, Malaysia

Smart Digital Community Research Alliance Universiti Teknologi Malaysia, 81310 UTM Johor Bahru, Johor, Malaysia
}

Article history:

Received 25 October 2020

Received in revised form 19 April 2021

Accepted 23 April 2021

Available online 1 June 2021

\section{Keywords:}

Model structure; Energy management; Temperature control

\begin{abstract}
The suitable application of innovative control strategies in Heating, Ventilation, and Airconditioning systems is important to improving the energy efficiency and maintenance of temperature set point to improve thermal comfort in buildings. The increased focus on energy savings and appropriate thermal comfort has resulted in the necessity for more dynamic approach to the use of these controllers. However, the design of these controllers requires the use of an accurate dynamic modelling. Substantial progresses have been made in the past on model development to provide better control strategy to ensure energy savings without sacrificing thermal comfort and indoor air quality in the Heating, Ventilation, and Air-conditioning systems. However, there are scarce model using the data driven approach in the Multi-circuit air-conditioning system. This research, carried out a study on the choice of a dynamic model for an operating centralized multi-circuit water-cooled package unit air-conditioning system using a system identification procedure. Baseline data were collected and analyzed, the model development was achieved by processing, estimating and validating the data in system identification. Result shows that the Autoregressive-moving average with exogenous terms (ARMAX) of the third order model, established the best model structure with the highest Best Fit and Lowest Mean Square Error.
\end{abstract}

\section{Introduction}

The global energy consumption is increasing rapidly, this has made it important to focus on both energy production and efficiency in order to ensure adequate supply. Human activity and population increase have been a major factor contributing to the continuous increase in energy consumption. The heating, ventilation, and air-conditioning (HVAC) system is the largest consumer of energy in the building sector and studies have also shown that it consumed about $50 \%$ of the total energy in the buildings [1].

Good control mechanism and optimization parameter has primarily been a foundation for an effective energy efficiency and good thermal comfort in the HVAC system. The HVAC system reliability and stability are extremely important such that minor system malfunctioning may lead to

\footnotetext{
* Corresponding author.

E-mail address: hayatiabdullah@utm.my
}

https://doi.org/10.37934/arfmts.83.2.1424 
bad consequences like energy wastage and thermal discomfort. It has been shown to be costeffective and efficient to improve the control algorithm to achieve greater performance [2]. Studies have also shown that performance degradation in HVAC system could be largely due to issues with the control automation system.

The use of the on/off control of temperature is common in the HVAC industry but it is not efficient in terms of thermal comfort and energy conservation. The proper control of temperature in a centralized air-conditioning system is very important and eventually leads to effective thermal comfort and energy efficiency. The HVAC system control generally is considered to be more challenging, complex and unique as compared to other types of control system because of its nonlinearity, disturbances, set points and time varying system dynamics [3]. The improvement in the control system requires that the system models must be accurate [4]. Modeling techniques are increasingly getting sophisticated with the emergence of advanced HVAC control systems. Considering the above-mentioned factors, it is important to implement a proper control procedure that will produce a good control system for the purpose of overcoming the inherent issues in the HVAC system. System identification is a crucial step in describing the dynamics of an air conditioning systems. This can be used as an effective tool in the design of air-conditioning controllers.

Many research studies on controlling air-conditioning system centers on a single refrigeration circuit system. There are very few research studies on a centralized multi-refrigeration circuit airconditioning system [5-7]. Therefore, this work is aimed at producing a dynamic model using system identification technique for the control of temperature in a centralized multi-refrigeration circuit water-cooled package unit air-conditioning system to ensure better energy efficiency while maintaining thermal comfort. The scope of this work is limited to a multi-refrigeration circuit water cooled package unit of a centralized air-conditioning system operational at block F54, Universiti Teknologi Malaysia.

A data driven approach is utilized in this study. A data acquisition procedure is set-up to collect data for indoor air temperature, indoor air humidity, outdoor air temperature, outdoor air humidity, cool supply air, warm return air and mixed air (a mixed of supply and return air). A power analyzer was used to collect the power consumption for the two compressors. A system identification toolbox in Matlab was used to process, estimate and validate the data using models such as the Autoregressive with exogenous terms (ARX), Autoregressive-moving average with exogenous terms (ARMAX), Box Jenkins and Output Error model. This research is focused on linear models as they have some advantages such as its simplicity and are much easier to deal with due to the potential of connecting them with physical models of the system [8].

\section{Description of Experimental Setup}

The air-conditioning system for this study is located at an office area in Block F54 of Universiti Teknologi Malaysia. A water-cooled air-conditioning unit (WCPU) housed in an Air Handling Unit (AHU) room cools the indoor space of the office. The water-cooled packaged unit consists of two refrigeration circuits. Each circuit consists of a direct expansion evaporator coil with expansion valve, water-cooled condenser, and a scroll type compressor. The two refrigeration circuits were designed to provide partial capacity in case of failure of any of the compressors. The WCPU is designed with a control panel where the on/off thermostat and power connections are located. The air distribution section consists of the blower and duct network which runs from the AHU to the indoor space. The indoor space is an office environment for official activities and the average occupants is 40 people. It is operated between 8:00 am to 5:00 pm Sunday to Wednesday and from 8:00 am to $3.30 \mathrm{pm}$ on 
Thursday. The air-conditioning system set-point temperature was $25^{\circ} \mathrm{C}$. Figure 1 (a) shows the layout of the indoor space with the location of the sensors and Figure 1(b) shows the Air Handling Unit.
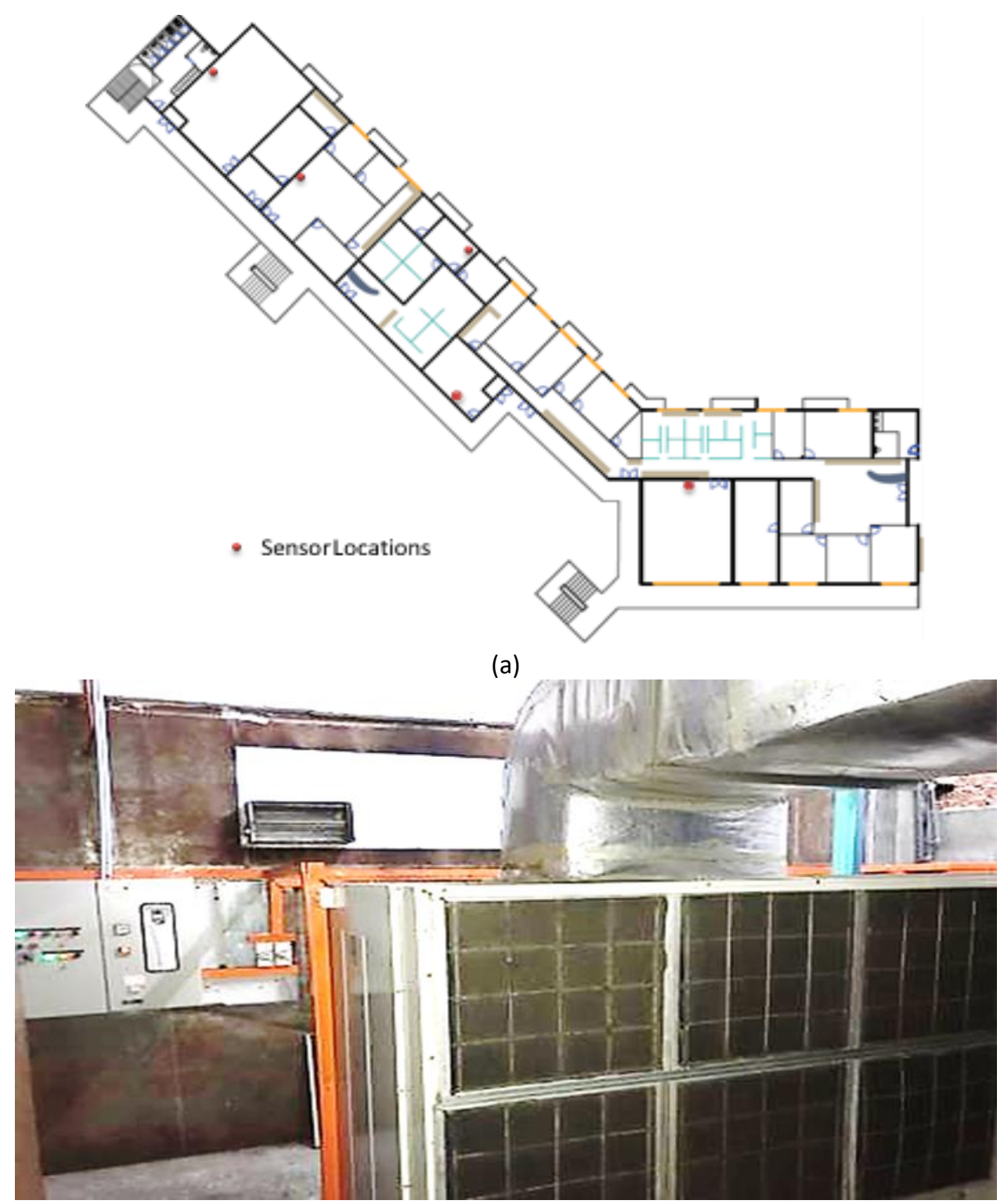

(b)

Fig. 1. (a) Layout of the indoor space (b) The air handling unit

\section{Data Collection}

The collection of data is an important process to developing an accurate model that represents as close as possible, the physics of the system. It involves logging of parameters including temperature and humidity at different locations as indicated in Figure 1 above. Data for the compressor power were collected for a period of two weeks. The data collected were categorized as input and output data which is a necessary step in the model development. The input data is the compressor power while the output data is the indoor room temperature. Table 1 lists the measured parameters and the measuring instruments. 


\section{Table 1}

Parameters measured and corresponding measuring instruments

\begin{tabular}{|c|c|c|c|c|}
\hline No & Parameter to be measured & Measuring Instrument & Type/Model & Accuracy \\
\hline 1 & Power input to compressor (kw) & Clamp-on Power Analyzer & Yokogawa IM CW240E & $0.5 \%$ of full scale \\
\hline \multirow[t]{2}{*}{2} & Indoor Temperature (5 & EasyLog wifi & Lascar electronic EL-WIFI- & $\pm 0.3^{\circ} \mathrm{C} / \pm 0.6^{\circ} \mathrm{F}$ \\
\hline & locations) & Temperature Data Logger & $\mathrm{TH}$ & \\
\hline \multirow[t]{2}{*}{3} & Outdoor Temperature & EasyLog wifi & Lascar electronic EL-WIFI- & $\pm 0.3^{\circ} \mathrm{C} / \pm 0.6^{\circ} \mathrm{F}$ \\
\hline & & Temperature Data Logger & $\mathrm{TH}$ & \\
\hline \multirow[t]{2}{*}{4} & Supply Air Volumetric flow rate & Air flow meter & Air velocity transducer & $\pm 2.0 \%$ of reading \\
\hline & & & 8455 series & $\begin{array}{l} \pm 0.5 \% \text { of full scale of } \\
\text { selected range }\end{array}$ \\
\hline \multirow[t]{2}{*}{5} & Relative Humidity of indoor Air & EasyLog wifi & \multirow{2}{*}{\multicolumn{2}{|c|}{ Lascar electronic EL-GFX-2 $\pm 2 \% \mathrm{RH}$}} \\
\hline & (5 locations) & Humidity Data Logger & & \\
\hline \multirow[t]{2}{*}{6} & Relative Humidity of outdoor & EasyLog wifi & \multirow{2}{*}{\multicolumn{2}{|c|}{ Lascar electronic EL-GFX-2 $\pm 2 \% \mathrm{RH}$}} \\
\hline & Air & Humidity Data Logger & & \\
\hline
\end{tabular}

Figure 2 below shows the installation of the measuring equipment used in the data collection of key parameters.

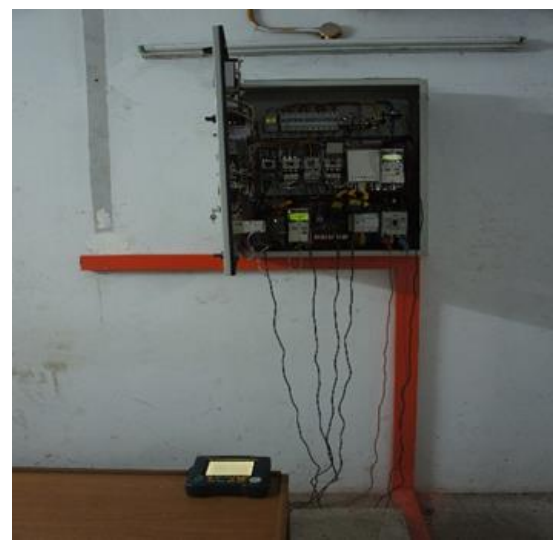

(a)

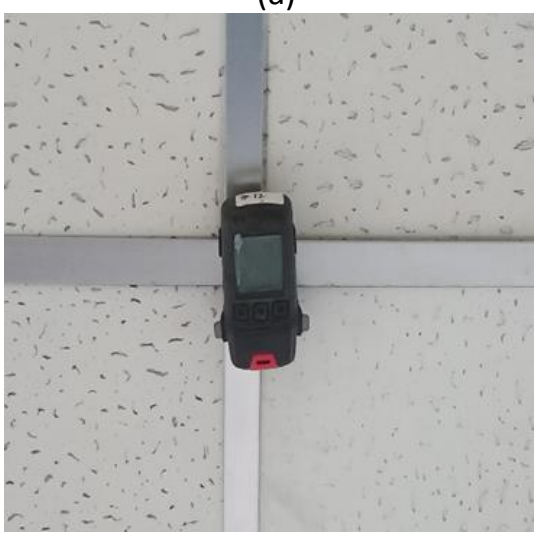

(c)

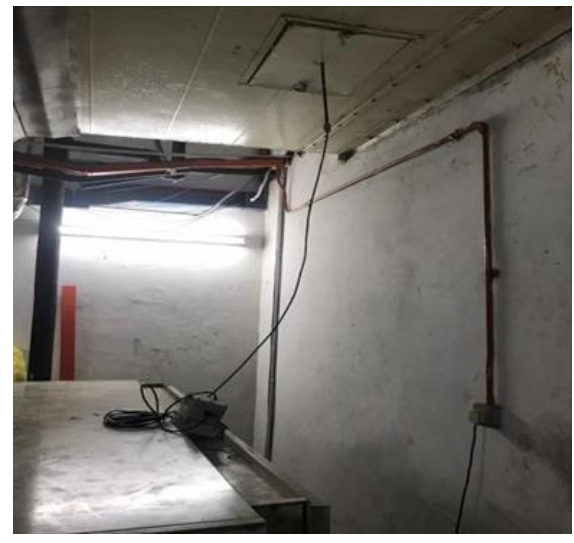

(b)

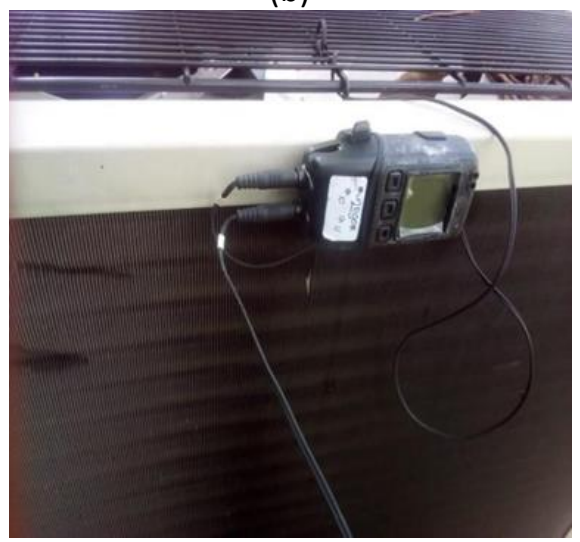

(d)

Fig. 2. (a) Power analyzer to measure compressor power (b) Air flow meter to measure supply air speed (c) Indoor temperature and humidity data logger (d) Outdoor temperature and humidity data logger

\section{System Identification}

Since the water-cooled package unit is an operational system, the data driven approach has been utilized in this study. Data driven models are developed by a process of system performance data 
collection, thereby establishing a relationship between the input and output variable. This can be achieved through the use of the system identification toolbox [9].

System identification is used for data analysis to obtain a model, which provides a mathematical representation of a physical system by measuring several variables of input and output and then formulating different model structures to relate as close as possible to the measured data. It also linearizes and reduces model complexity [10].

In this study, the main class of model structures used is the linear parametric model. The method of determining the right linear parametric model from the observed input-output data involves the following [11]

- Input-output data measurement, through experimental setup

- Pre-processing of the collected data, by removing means and trend

- Model structure selection and parameter estimation

- Model validation

\subsection{Model Development with Linear Parametric Models}

After the data have been analyzed using the system identification toolbox, a large collection of models with different orders and structures are obtained. There are different structures discussed in the literature. In selecting the best model that provides good room temperature prediction, the model performance criteria such as best fit percentage, mean squared error and final prediction error between model output and real measurements were used. The model output which is the indoor temperature are modelled by Box Jenkins, Output Error, State Space, ARX and ARMAX models. The general parametric model structure is represented by Eq. (1) [12].

$\mathrm{A}(\mathrm{q}) \mathrm{y}(\mathrm{t})=\frac{\mathrm{B}(\mathrm{q})}{\mathrm{F}(\mathrm{q})} \mathrm{u}(\mathrm{t}-\mathrm{nk})+\frac{C(\mathrm{q})}{D(q)} e(t)$

where $u(t)$ is the input, $y(t)$ is the output, $e(t)$ is the error, and $A(q), B(q), C(q), D(q)$ and $F(q)$ are polynomials in the shift-operator, $\mathrm{q}-1$ as follows

$$
\begin{aligned}
& \mathrm{A}(q)=1+a 1 q-1+\cdots+\text { ana }-n a \\
& \mathrm{~B}(q)=b 1+b 2 q-1+\cdots+b n b q-(n b-1) \\
& \mathrm{C}(q)=1+c 1 q-1+\cdots+c n c q-n c \\
& \mathrm{D}(q)=1+d 1 q-1+\cdots+d n d q-n d \\
& \mathrm{~F}(q)=1+f 1 q-1+\cdots+f n f q-n f
\end{aligned}
$$

The orders of the polynomials are $n a, n b, n c, n d$ and $n f$ respectively.

\subsubsection{ARX model structure}

This model structure is the simplest out of all the model structure. It is autoregressive with exogenous terms and it has the following structure as given by Eq. (2) 
The ARX model is made up of the AutoRegressive part $A(q) y(t)$ and the eXogenous part $B(q) u(t)$ The ARX model can be explicitly written in the following form:

$\mathrm{y}(t)+a 1 y(t-1)+\cdots+\operatorname{anay}(t-n a)=b 1 u(t-n k)+\cdots+b n b u(t-n b-n k+1)+e(t)$

where $n a=$ number of poles; $n b=$ number of zeroes plus $1 ;(t-1) \ldots y(t-n a)=$ previous outputs on which the current output depends; $(t-n k) \ldots u(t-n k-n b+1)=$ previous and delayed inputs on which the current output depends

\subsubsection{ARMAX model structure}

This model is the Autoregressive-moving average with exogenous terms. According to [13] which stated that the main characteristics and advantages of an ARMAX model over the ARX model include flexibility in the disturbance modelling and coping with the presence of noise. It also features modest computational complexity with high accuracy, model stability and accurate model parameter estimation.

The input-output relationship for the ARMAX model is:

$\mathrm{y}(t)+a 1 y(t-1)+\cdots+\operatorname{anay}(t-n a)=$

$b 1(t-n k)+\cdots+b n b u(t-n b-n k+1)+c 1 e(t-1)+\cdots+c n c e(t-n c)+e(t)$

The ARMAX model has the same feature with ARX model but with additional moving average part $C(q) e(t)$. The ARMAX model structure is represented by Eq. (5)

$A(q) y(t)=B(q) u(t-n k)+C(q) e(t)$

\subsubsection{Output error (OE) model}

The Output Error model structure is used in the case when the process output is disturbed by only white measurement noise. In most cases, the input and noise are subject to different dynamics, therefore modelling is achieved by establishing the relationship between the inputs and the undisturbed output [14]. The OE model structure is represented in Eq. (4) as follows:

$y(t)=\frac{B(q)}{F(q)} u(t-n k)+e(t)$

\subsubsection{Box Jenkins (BJ) model}

Box Jenkins model provides completely independent parameterization for the dynamics and the noise using a rational polynomial function. Eq. (5) below represents the BJ structure [14]:

$y(t)=\frac{B(q)}{F(q)} u(t-n k)+\frac{C(q)}{D(q)} e(t)$ 


\subsubsection{State-space model structures}

The state space model can be used for the investigation of the dynamic characteristics of the system which is important for the control system. It shows the relationship between the input and output variables in the model and expressing it in the form of a matrix convenient for computer calculations. One of the drawbacks of the model structure is that some characteristics of the physical essence of the system might not be well represented [15]. The state-space models have the following general structures:

Discrete time

$$
\begin{aligned}
& x(t+T s)=A x(t)+B u(t)+K e(t) \\
& y(t)=C x(t)+D u(t)+e(t)
\end{aligned}
$$

\section{Results}

Data were collected during the operating hours of the air-conditioning system at block F54, Universiti Teknologi Malaysia. Data analysis and preparation were carried out and followed by model structure selection, model estimation and model validation. All models were tested with different orders and compared to each other. The best model is selected based on the following model validation criteria [16]

- Best Fit percentage,

- Lowest Mean Square Error and

- Final Prediction Error.

According to Jönsson [11], the best fit percentage and mean square error is presented as

$B F=\left(1-\frac{\operatorname{norm}(y-\hat{y})}{\operatorname{norm}(y-\bar{y})}\right) \times 100$

$\operatorname{MSE}=1 \sum_{N}^{N} \underset{i=1}{(y i-\hat{y} i)^{2}}$

where $\hat{y}=$ measured output; $\bar{y}=$ simulated output.

According to Mu et al., [16], the Final Prediction Error is presented as

$F P E=\operatorname{det}\left(\frac{1}{N} E^{T} E\right)\left(\frac{1+\frac{n p}{N}}{1-\frac{n p}{N}}\right)$

where $\mathrm{N}=$ Number of values in the estimation data set $\mathrm{E}=$ Matrix of prediction errors; $\mathrm{np}=$ total number of estimated parameters.

Table 2 below shows the best fit, mean square error, and final prediction error for all the models used in the first order. The results showed that the Box Jenkins model has the highest Best Fit of 99.12\% and Lowest Mean Square Error and Final Prediction Error. Other models except for the Output Error model also performed well. Figure 3 shows the best fit for all the models in the first order between measured and the predicted output. 
Table 2

Results for first order model structures

\begin{tabular}{llll}
\hline Model Structure & Best Fit (\%) & $\begin{array}{l}\text { Final Prediction } \\
\text { Error }\end{array}$ & $\begin{array}{l}\text { Mean Square } \\
\text { Error }\end{array}$ \\
\hline ARX & 99.02 & 0.0002454 & 0.0002445 \\
ARMAX & 98.09 & 0.0001654 & 0.001649 \\
Box Jenkins & 99.12 & 0.0001397 & 0.000139 \\
Output Error & 29.5 & 0.3890 & 0.3882 \\
State Space & 99.03 & 0.0002446 & 0.0002442 \\
\hline
\end{tabular}

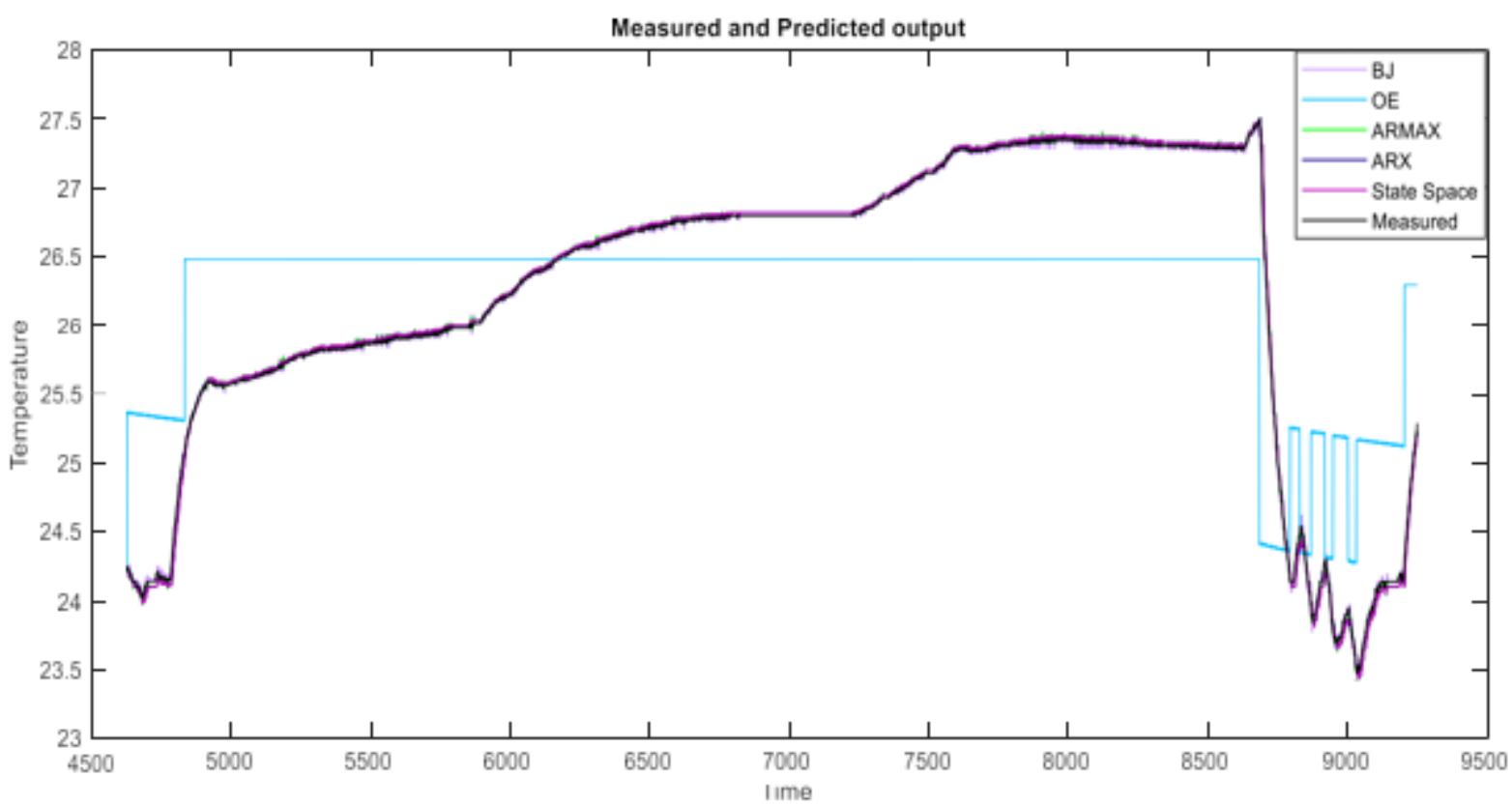

Fig. 3. First order model performance

In the second order model as shown in Table 3, the ARMAX model has the best fit with $99.22 \%$ and the lowest Mean Square Error and Final Prediction Error. The Output Error model performance was the lowest with a best fit value of $35.89 \%$. Figure 4 shows the best fit for all the models in the second order between measured and the predicted output.

Table 3

Results for second order model structures

\begin{tabular}{llll}
\hline Model Structure & Best Fit (\%) & $\begin{array}{l}\text { Final Prediction } \\
\text { Error }\end{array}$ & $\begin{array}{l}\text { Mean Square } \\
\text { Error }\end{array}$ \\
\hline ARX & 99.09 & 0.0001497 & 0.000149 \\
ARMAX & 99.22 & 0.000119 & 0.001186 \\
Box Jenkins & 99.15 & 0.0001389 & 0.0001382 \\
Output Error & 35.89 & 0.2622 & 0.2615 \\
State Space & 99.21 & 0.0001199 & 0.0001195 \\
\hline
\end{tabular}




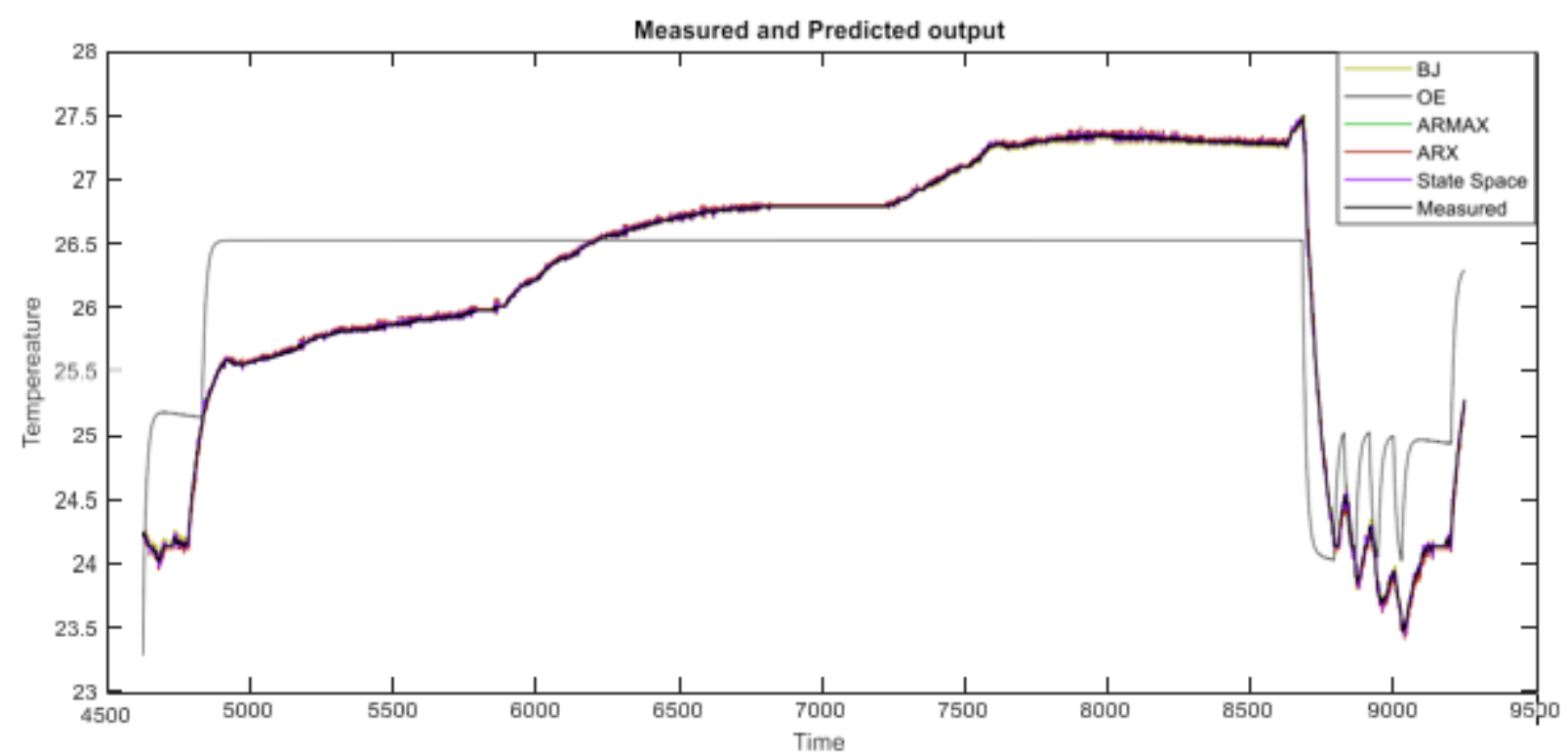

Fig. 4. Second order model performance

Table 4 shows the results for 3rd order model structures. The ARMAX model has the best fit with a value of $99.23 \%$. It also has the lowest Mean Square Error and Final Prediction Error. The Output Error model has the lowest best fit of $36.07 \%$. Figure 5 shows the best fit for all the models in the third order between measured and the predicted output.

\section{Table 4}

Result for third order model structures

\begin{tabular}{llll}
\hline Model Structure & Best Fit (\%) & $\begin{array}{l}\text { Final Prediction } \\
\text { Error }\end{array}$ & $\begin{array}{l}\text { Mean Square } \\
\text { Error }\end{array}$ \\
\hline ARX & 99.16 & 0.0001365 & 0.0001358 \\
ARMAX & 99.23 & 0.0001161 & 0.0001156 \\
Box Jenkins & 98.3 & 0.0002338 & 0.0002324 \\
Output Error & 36.07 & 0.258 & 0.2571 \\
State Space & 99.22 & 0.000117 & 0.0001164 \\
\hline
\end{tabular}

Comparing the results, the lowest performing model for all the three order is the Output Error model. Generally, the ARX, ARMAX, Box Jenkins and State Space models performed well for all the order and gives sufficiently good results. The ARMAX 3rd order model was found to have the overall best fit with a value of $99.23 \%$. This model also has the lowest Mean Square Error with a value of 0.00011156 and the lowest Final Prediction Error with a value of 0.0001161 . The model with the best fit, smallest mean square error and final prediction error should be selected [8]. Therefore, in this study the ARMAX 3rd order model is selected as the model that best describes the dynamics of the system. 


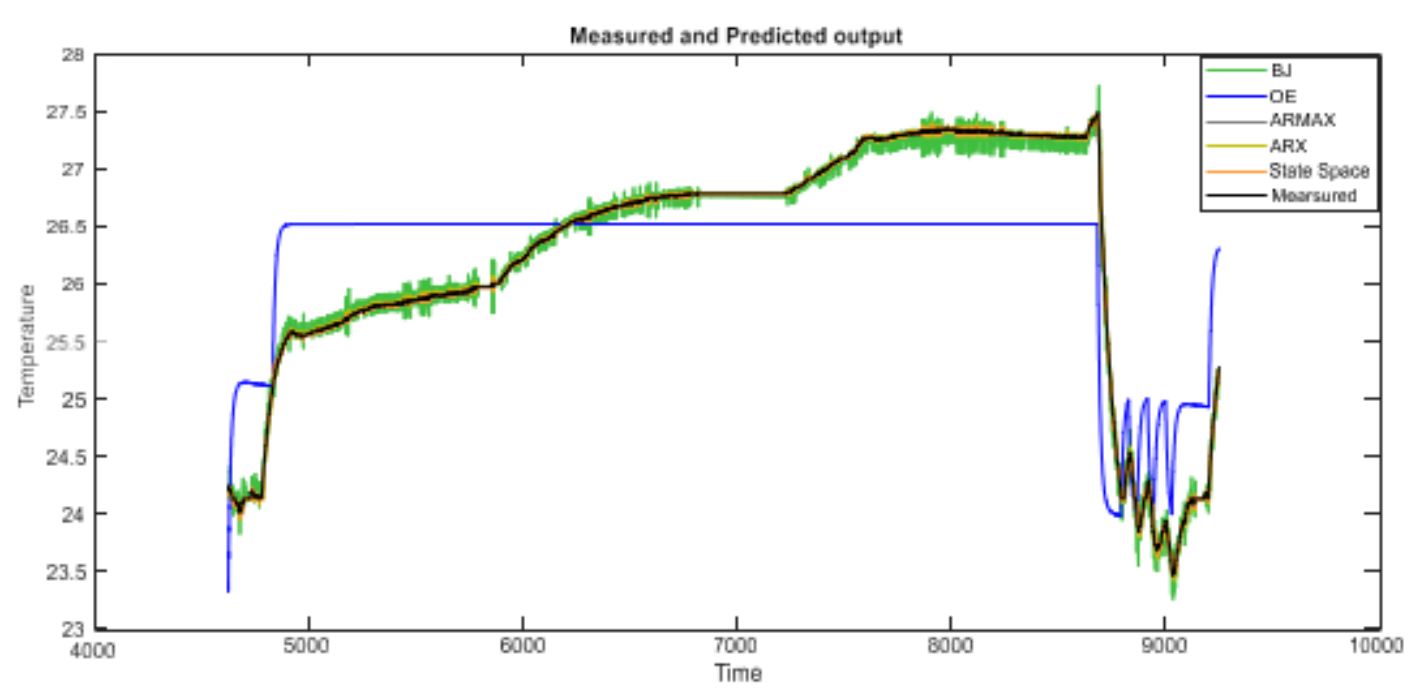

Fig. 5. Third order model performance

\section{Conclusion}

Suitable control strategies are important in order to maintain a desired indoor temperature in air-conditioned buildings. The selection of an accurate dynamic model of the system is critical in developing a control strategy that will reduce energy consumption while providing the desired indoor temperature for thermal comfort. This study will be useful in the building and energy management research area especially in the design of controllers for applications in the HVAC system. Most conventional controllers are only reliable if the system parameter does not change too much [17]. Considering the nature of the air-conditioning system which depends on many factors such as the outdoor condition, occupancy variation and seasonal changes, the predictive control method is highly suitable. The most common is the model predictive control (MPC) which gives the possibility to predict variables such as outdoor temperature and expected occupancy depending on the model used for the control strategy. The MPC will be a focus of the future work for this study. It is also important to note that the results of the model obtained in this study is only applicable for the experimental set-up as described in this study. However, similar procedures can be followed to obtain dynamic models for other centralized air-conditioning systems in buildings.

\section{Acknowledgement}

This work was supported by the Ministry of Higher Education Malaysia and Universiti Teknologi Malaysia through the Translational Research Grant (UTM-TRG) Vot $4 J 337$.

\section{References}

[1] Bakar, Nur Najihah Abu, Mohammad Yusri Hassan, Hayati Abdullah, Hasimah Abdul Rahman, Md Pauzi Abdullah, Faridah Hussin, and Masilah Bandi. "Energy efficiency index as an indicator for measuring building energy performance: A review." Renewable and Sustainable Energy Reviews 44 (2015): 1-11. https://doi.org/10.1016/i.rser.2014.12.018

[2] Behrooz, Farinaz, Norman Mariun, Mohammad Hamiruce Marhaban, Mohd Amran Mohd Radzi, and Abdul Rahman Ramli. "Review of control techniques for HVAC systems-Nonlinearity approaches based on Fuzzy cognitive maps." Energies 11, no. 3 (2018): 495.

[3] Afram, Abdul, and Farrokh Janabi-Sharifi. "Review of modeling methods for HVAC systems." Applied Thermal Engineering 67, no. 1-2 (2014): 507-519. https://doi.org/10.1016/i.applthermaleng.2014.03.055

[4] Afroz, Zakia, G. M. Shafiullah, Tania Urmee, and Gary Higgins. "Modeling techniques used in building HVAC control systems: A review." Renewable and sustainable energy reviews 83 (2018): 64-84. https://doi.org/10.1016/i.rser.2017.10.044 
[5] Ko, Young-Sun, and Sang Tae No. "A study on comparison of building energy simulation and measurement results for a city hall." Journal of Building Construction and Planning Research 3, no. 01 (2015): 1. https://doi.org/10.4236/jbcpr.2015.31001

[6] Lü, Xiaoshu, Tao Lu, Charles J. Kibert, and Martti Viljanen. "Modeling and forecasting energy consumption for heterogeneous buildings using a physical-statistical approach." Applied Energy 144 (2015): 261-275. https://doi.org/10.1016/i.apenergy.2014.12.019

[7] da Graca, G. Carrilho, Paul F. Linden, and Philip Haves. "Design and testing of a control strategy for a large, naturally ventilated office building." Building Services Engineering Research and Technology 25, no. 3 (2004): $223-239$. https://doi.org/10.1191/0143624404bt107oa

[8] Mustafaraj, Giorgio, Gordon Lowry, and Jie Chen. "Prediction of room temperature and relative humidity by autoregressive linear and nonlinear neural network models for an open office." Energy and Buildings 43, no. 6 (2011): 1452-1460. https://doi.org/10.1016/i.enbuild.2011.02.007

[9] Turner, W. J. N., A. Staino, and B. Basu. "Residential HVAC fault detection using a system identification approach." Energy and Buildings 151 (2017): 1-17. https://doi.org/10.1016/i.enbuild.2017.06.008

[10] Albert, T. P., W. L. Chan, T. T. Chow, and W. L. Tse. "New HVAC control by system identification." Building and Environment 30, no. 3 (1995): 349-357. https://doi.org/10.1016/0360-1323(94)00063-X

[11] Synnøve Jönsson, Ida. "System identification for control of temperature and humidity in buildings." (2015).

[12] Ljung, Lennart. "System identification." Wiley encyclopedia of electrical and electronics engineering (1999): 1-19. https://doi.org/10.1002/047134608X.W1046.pub2

[13] Florakis, A., S. D. Fassois, and F. M. Hemez. "MIMO LMS-ARMAX identification of vibrating structures-part II: a critical assessment." Mechanical Systems and Signal Processing 15, no. 4 (2001): 737-758. https://doi.org/10.1006/mssp.2000.1385

[14] Mustafaraj, Giorgio, Jie Chen, and Gordon Lowry. "Development of room temperature and relative humidity linear parametric models for an open office using BMS data." Energy and Buildings 42, no. 3 (2010): 348-356. https://doi.org/10.1016/j.enbuild.2009.10.001

[15] McKelvey, Tomas, Anders Helmersson, and Thomas Ribarits. "Data driven local coordinates for multivariable linear systems and their application to system identification." Automatica 40, no. 9 (2004): 1629-1635. https://doi.org/10.1016/i.automatica.2004.04.015

[16] Mu, Biqiang, Tianshi Chen, and Lennart Ljung. "On the input design for kernel-based regularized LTI system identification: Power-constrained inputs." In 2017 IEEE 56th Annual Conference on Decision and Control (CDC), pp. 5262-5267. IEEE, 2017. https://doi.org/10.1109/CDC.2017.8264437

[17] Scotton, Francesco, Lirong Huang, Seyed A. Ahmadi, and Bo Wahlberg. "Physics-based modeling and identification for HVAC systems?." In 2013 European Control Conference (ECC), pp. 1404-1409. IEEE, 2013. https://doi.org/10.23919/ECC.2013.6669134 